\title{
HUBUNGAN STATUS VEGETARIAN DENGAN DERAJAT SINDROMA PRAMENSTRUASI PADA REMAJA
}

\author{
Ardiati Setianingsih, Martha Irene Kartasurya ${ }^{*}$ \\ Program Studi Ilmu Gizi Fakultas Kedokteran Universitas Diponegoro \\ Jl.Dr.Sutomo No.14, Semarang, Telp (024) 8453708, Email : gizifk@undip.ac.id
}

\begin{abstract}
Background: Recently, some adolescents has already implemented vegetarian diet. Vegetarian diets are rich in fiber, magnesium, and vitamin B6 which are associated to the low incidence of premenstrual syndrome. Premenstrual syndrome in adolescents may inhibit their social and academic activities. This study aimed to investigate the association between vegetarian status and premenstrual syndrome among adolescents.

Methods: This study used a cross sectional design. The subjects were 22 vegetarian and 22 non-vegetarian adolescents who were selected purposively. The dependent variable was premenstrual syndrome score and, the independent variable was the vegetarian status. The confounding variables were family history of premenstrual syndrome and physical activity. Data on premenstrual syndrome, physical activity, and family history were retrieved by interviews using structured questionnaires. Data fiber, magnesium, and vitamin B6 intakes were obtained by Semi Quantitative Food Frequency Questionnaires. The difference in fiber intake was tested by independent t-test. The difference in premenstrual syndrome, magnesium, vitamin B6 were tested by Mann-Whitney test, and the difference in family history of premenstrual syndrome and physical activity were tested by fisher-exact test. Ancova test is used to control confounding variables.

Results: There was no difference in premenstrual syndrome score $(p=0,274)$ between vegetarian $(12.5 \pm 11.1)$ and non-vegetarian (17 \pm 9.3$)$ adolescents. There were no differences in fiber $(p=0,133)$, magnesium $(p=0,372)$, vitamin B6 ( $p=0,621)$ intakes between vegetarian and non-vegetarian adolescents. There was a difference in family history of premenstrual syndrome $(p=0,004)$ between vegetarian $(0 \%)$ and non-vegetarian $(36,4 \%)$. There was no difference in physical activities $(p=0,698)$ between vegetarian and nonvegetarian. There was no difference in premenstrual syndrome scores between vegetarian $(15,4 \pm 2,3)$ and nonvegetarian $(16,5 \pm 2,3)$ after controlled by family history of premenstrual syndrome.

Conclusions: There was no association between vegetarian status and premenstrual syndrome scores before and after controlled for family history of premenstrual syndrome.
\end{abstract}

Keywords: premenstrual syndrome; vegetarian; vitamin B6; magnesium; fiber

\begin{abstract}
ABSTRAK
Latar Belakang : Sebagian remaja sudah mulai menerapkan diet vegetarian. Diet vegetarian yang kaya akan serat, magnesium dan vitamin B6 berhubungan dengan sindrom pramenstruasi. Sindrom pramenstruasi pada remaja dapat menghambat aktivitas sosial dan akademik. Penelitian ini bertujuan untuk menganalisis hubungan derajat sindrom pramenstruasi dengan status vegetarian pada remaja.

Metode : Desain penelitian adalah cross sectional. Subjek terdiri dari 22 remaja vegetarian dan 22 remaja nonvegetarian yang dipilih secara purposive. Variabel dependen adalah sindrom pramenstruasi, variabel independen adalah status vegetarian. Variabel perancu adalah riwayat sindrom pramenstruasi keluarga dan aktivitas fisik. Data sindrom pramenstruasi, aktivitas fisik, dan riwayat keluarga diperoleh dengan wawancara menggunakan kuesioner terstruktur. Data asupan serat, magnesium, dan vitamin B6 diperoleh dengan Semi Quantitative Food Frequency. Perbedaan sindrom pramenstruasi, magnesium, vitamin B6 diuji menggunakan uji Mann-Whitney, riwayat sindrom pramenstruasi keluarga dan aktivitas fisik diuji menggunakan uji fisher-exact. Uji ancova digunakan untuk mengontrol variabel perancu.

Hasil : Tidak terdapat perbedaan skor sindrom pramenstruasi $(p=0,274)$ antara remaja vegetarian $(12,5 \pm 11,1)$ dan nonvegetarian $(17 \pm 9,3)$. Tidak terdapat perbedaan asupan serat $(p=0,133)$, magnesium $(p=0,372)$, vitamin $\mathrm{B} 6$ $(p=0,621)$ antara remaja vegetarian dan non-vegetarian. Ada perbedaan riwayat sindrom pramenstruasi keluarga $(p=0,004)$ pada kelompok vegetarian $(0 \%)$ dan nonvegetarian $(36,4 \%)$. Tidak ada perbedaan aktivitas fisik $(p=0,698)$ antara remeja vegetarian dan nonvegetarian. Setelah dikontrol dengan riwayat sindrom pramenstruasi keluarga, skor sindrom pramenstruasi tetap tidak berbeda $(15,4 \pm 2,3)$ untuk vegetarian dan nonvegetarian $(16,5 \pm 2,3)$. Simpulan : Tidak ada hubungan sindrom pramenstruasi antara vegetarian dan nonvegetarian sebelum dan sesudah dikontrol oleh riwayat sindrom pramenstruasi keluarga.
\end{abstract}

Kata kunci : sindrom pramenstruasi; vegetarian; vitamin B6; magnesium; serat

\footnotetext{
${ }^{*}$ Penulis Penanggungjawab
} 


\section{PENDAHULUAN}

Premenstrual Syndrome (PMS) atau sindrom pramenstruasi adalah gangguan kesehatan yang dialami oleh wanita usia subur, ditandai dengan gejala yang tidak nyaman sebelum menstruasi. Biasanya terjadi selama $7-10$ hari dan berakhir 4 hari setelah menstruasi mulai. ${ }^{1}$ Sindrom pramenstruasi pada remaja dapat menurunkan tingkat kehadiran di kelas, terganggunya aktivitas sehari-hari, dan dapat mempengaruhi aktivitas akademik remaja tersebut. $^{2,3}$

Penelitian Antai et al menunjukkan tingkat kejadian sindrom pramenstruasi pada 200 mahasiswi usia 16 - 31 tahun di Universitas Calabar, Nigeria sebesar $85,5 \% .^{4}$ Penelitian lainnya oleh Takeda et al menunjukkan 93,5\% mengalami sindrom pramenstruasi ringan, 5,3\% mengalami sindrom pramenstruasi tingkat sedang hingga berat dan 1,2 \% mengalami PMDD (Premenstrual Dysphoric Disorder) dari 1152 wanita Jepang yang berpartisipasi dalam studi populasi ini. $^{5}$

Dewasa ini diet vegetarian sudah menjadi bagian dari gaya hidup masa kini. Hal ini tidak lain karena diet vegetarian mampu menurunkan risiko terjadinya penyakit degeneratif dan khususnya sindrom pramenstruasi pada wanita usia produktif. Penelitian Barnard menyimpulkan bahwa diet vegetarian berhubungan dengan peningkatan serum hormon reproduksi yang mengikat konsentrasi globulin dan penurunan berat badan, durasi dismenore, dan durasi keluhan sindrom pramenstruasi. ${ }^{6}$

Pada orang yang melakukan diet vegetarian diketahui serat yang dikonsumsi lebih banyak daripada yang tidak melakukan diet vegetarian. Menurut survei NHANES 1999 - 2004, serat yang dikonsumsi oleh vegetarian $(20,3 \pm 0,6 \mathrm{~g})$ dibandingkan dengan nonvegetarian $(15,4 \pm 0,2 \mathrm{~g})$. Serat ini berasal dari lignin, legume, sereal gandum, buah-buahan, dan sayur. ${ }^{7}$ Remaja yang melakukan diet vegetarian, sebagian besar sudah menyadari pentingnya diet vegetarian untuk dirinya.

Ulasan dari berbagai artikel penelitian oleh Rejina Diekemper menyatakan bahwa diet vegetarian yang tinggi serat mengekskresikan lebih banyak estrogen pada fesesnya dan kadar estrogen bebas dalam darah $50 \%$ lebih rendah daripada omnivore. Hal ini mengakibatkan vegetarian lebih sedikit yang mengalami sindrom pramenstruasi. ${ }^{8}$

Magnesium merupakan faktor protektif terhadap kejadian sindrom pramenstruasi bersama dengan piridoksin dan niasin mensintesis konjugasi hormon estrogen. Magnesium berperan meningkatkan aktivitas enzim glucuronyl transferase. Suatu enzim yang terlibat proses glukuronidasi hepatik estrogen. Pada saat kadar magnesium dalam darah rendah maka proses ini tidak berjalan dengan baik. Survei NHANES 1999 - 2004 menunjukkan magnesium pada kelompok vegetarian $(322 \pm 5 \mathrm{mg})$ lebih tinggi dibandingkan kelompok nonvegetarian $(281 \pm 2 \mathrm{mg})$.

Magnesium selain berfungsi pada proses glukuronidasi hepatik estrogen, juga ikut mengaktivasi piridoksin ke bentuk aktifnya yaitu pyridoxal phosphate. ${ }^{9}$ De Souza et al memperlihatkan efek $200 \mathrm{mg}$ magnesium dan 50 mg piridoksin dapat meringankan gejala sindrom pramenstruasi seperti kelelahan, iritabilitas dan kecemasan pada 44 orang wanita yang rata-rata berusia 33 tahun dalam satu kali siklus menstruasi. ${ }^{10}$ Hasil survei NHANES $1999-2004$ piridoksin kelompok vegetarian $(1,8 \pm 0,1) \mathrm{mg}$ dibandingkan nonvegetarian $(1,9 \pm 0) \mathrm{mg}$.

Piridoksin berperan dalam biosintesis neurotransmitter dan steroid. $^{11}$ Salah satu contohnya biosintesis steroid adalah serotonin. Serotonin berperan penting pada kejadian sindrom pramenstruasi. Saat kadar piridoksin rendah dalam darah, maka biosinteis serotonin terganggu, sehingga memicu ovulasi terlalu awal dan terjadi pergantian pola estrogen dan progesteron.

\section{METODE}

Penelitian dilakukan selama bulan September 2012 di Indonesia Vegetarian Society (IVS) Jakarta. Penelitian ini termasuk dalam lingkup gizi masyarakat dan merupakan penelitian observasional dengan desain cross sectional.

Populasi terjangkau dalam penelitian ini adalah semua remaja di Indonesia Vegetarian Society (IVS) Jakarta untuk kelompok vegetarian. Kelompok nonvegetarian diperoleh dari masyarakat umum di Jakarta. Sampel yang didapatkan dalam penelitian ini sebanyak 44 orang, 22 orang untuk setiap kelompok. Metode pengambilan sampel adalah purposive sampling, kriteria inklusi usia $12-21$ tahun, IMT normal antara $-2-+2$ SD standar WHO, tidak mengalami tekanan psikis dan menjalani vegetarian minimal 6 bulan untuk inklusi kelompok vegetariannya.

Variabel dalam penelitian ini meliputi variabel bebas yaitu status vegetarian kelompok vegetarian dan non vegetarian, variabel terikat yaitu derajat sindrom pramenstruasi, serta variabel perancu yaitu riwayat sindrom pramenstruasi keluarga dan aktifitas fisik. 
Asupan magnesium, piridoksin, dan serat diperoleh dari hasil wawancara dengan metode Semi Quantitative Food Frequency Questionnaire (SQFFQ) dengan alat bantu food model. Data sindrom pramenstruasi didapat dengan menggunakan kuesioner dari Steiner et al. ${ }^{13}$ Skala variabel yang digunakan adalah skala rasio dan dinyatakan dengan skoring. Data riwayat sindrom pramenstruasi keluarga didapatkan dari hasil wawancara. Skala variabel ini adalah nominal yang dinyatakan dengan pernyataan ada atau tidak. Data aktifitas fisik diperoleh dari pengisian kuesioner aktifitas fisik 24 jam dari WHO. Skala variabel aktifitas fisik adalah ordinal yang dinyatakan dengan ringan, sedang, dan berat.

Data-data yang sudah diperoleh meliputi asupan magnesium, asupan piridoksin, dan asupan serat dianalisis dengan program Nutrisurvey 2005. Analisis univariat dilakukan untuk mendeskripsikan data sindrom pramenstruasi, data asupan magnesium, data asupan piridoksin dan data asupan serat. Data tersebut diuji kenormalannya dengan menggunakan uji SaphiroWilk. Analisis bivariat dilakukan dengan menggunakan uji Mann-Whitney untuk uji beda skor sindrom pramenstruasi, asupan magnesium dan vitamin B6. Uji independent T-test untuk uji beda asupan serat dan uji fisher-exact untuk variabel aktivitas fisik dan riwayat sindrom pramenstruasi keluarga. Analisis multivariat menggunakan uji ancova untuk mengontrol variabel perancu.

\section{HASIL PENELITIAN Karakteristik Subjek Penelitian}

Sebagian besar subjek vegetarian $(59,1 \%)$ telah menjalankan dietnya lebih dari 2 tahun, sedangkan sebanyak $72,8 \%$ subjek vegetarian menjalankan diet vegetarian jenis lacto-ovo vegetarian. Rerata lama menstruasi sejak menarche $4,6 \pm 1,8$ tahun untuk nonvegetarian dan untuk vegetarian 3,5 $\pm 2,3$ tahun. Karakteristik subjek selengkapnya dapat dilihat pada Tabel 1 dan Tabel 2 .

Tabel 1. Karakteristik subjek penelitian menurut usia, dan lama menstruasi sejak menarche

\begin{tabular}{lcc}
\hline \multirow{2}{*}{ Karakteristik } & Vegetarian $(\mathrm{n}=22)$ & Non-vegetarian $(\mathrm{n}=22)$ \\
\cline { 2 - 3 } & Rerata \pm Standar & Rerata \pm Standar \\
& Deviasi & Deviasi \\
\hline Umur (tahun) & $16,5 \pm 2,3$ & $16,5 \pm 1,9$ \\
Lama menstruasi & $3,5 \pm 2,3$ & $4,6 \pm 1,8$ \\
sejak menarche & & \\
(tahun) & & \\
\hline
\end{tabular}

Tabel 2. Karakteristik subjek penelitian kelompok vegetarian menurut jenis vegetarian, dan lama vegetarian

\begin{tabular}{lcc}
\hline Karakteristik & \multicolumn{2}{c}{ Vegetarian $(\mathrm{n}=22)$} \\
\cline { 2 - 3 } & $\mathrm{n}$ & $\%$ \\
\hline Jenis vegetarian & 2 & \\
Lacto vegetarian & 3 & 9,1 \\
Ovo vegetarian & 16 & 13,6 \\
Lacto-ovo vegetarian & 1 & 72,8 \\
Vegan & 22 & 4,5 \\
\hline Total & & 100,0 \\
\hline Lama menjadi vegetarian & 2 & \\
6 bulan & 3 & 9,1 \\
1 tahun & 4 & 13,6 \\
2 tahun & 13 & 18,2 \\
$>2$ tahun & 22 & 59,1 \\
\hline Total & & 100,0 \\
\hline
\end{tabular}

Asupan Zat Gizi Subjek
Uji beda asupan serat, magnesium dan piridoksin dapat dilihat pada Tabel 3 . 
Tabel 3. Uji beda asupan serat, magnesium dan piridoksin

\begin{tabular}{|c|c|c|c|}
\hline \multirow[b]{2}{*}{ Variabel } & Vegetarian $(n=22)$ & Non-vegetarian $(n=22)$ & \multirow[b]{2}{*}{$p$ value } \\
\hline & $\begin{array}{c}\text { Median } \pm \text { Standar } \\
\text { Deviasi }\end{array}$ & Median \pm Standar Deviasi & \\
\hline Serat (gr) & $12,9 \pm 6,8$ & $9,8 \pm 4,5$ & $0,133^{*}$ \\
\hline Magnesium (mg) & $245,3 \pm 190,2$ & $222,9 \pm 767,4$ & $0,372 * *$ \\
\hline Piridoksin (mg) & $0,8 \pm 0,5$ & $1,1 \pm 1,1$ & $0,621 * *$ \\
\hline
\end{tabular}

*Uji independent T-test

**Uji Mann-Whitney

Hasil penelitian menunjukkan tidak ada

Pengelompokkan berdasarkan rekomendasi dari perbedaan asupan serat, magnesium, dan Widya Karya Pangan Nasional 2004 ditunjukkan piridoksin antara kedua kelompok. di Tabel 4.

Tabel 4. Kategori tingkat asupan serat, magnesium dan piridoksin

\begin{tabular}{lcccc}
\hline Asupan & \multicolumn{2}{c}{ Vegetarian $(\mathrm{n}=22)$} & \multicolumn{2}{c}{$\begin{array}{c}\text { Non Vegetarian } \\
(\mathrm{n}=22)\end{array}$} \\
\cline { 2 - 5 } & $\mathrm{n}$ & $\%$ & $\mathrm{n}$ & $\%$ \\
\hline Serat (gr) & & & 21 & 95,5 \\
Kurang (<20) & 20 & 90,9 & 1 & 4,5 \\
Cukup (20-35) & 2 & 9,1 & 0 & 0 \\
Lebih (> 35) & 0 & 0 & & \\
\hline Magnesium (mg) & & & 13 & 59,1 \\
Kurang (<240) & 11 & 50 & 8 & 36,4 \\
Cukup (240-350) & 4 & 18,2 & 1 & 4,5 \\
Lebih (> 350) & 7 & 31,8 & & \\
\hline Piridoksin (mg) & & & & 36,4 \\
Kurang (<1) & 12 & 54,5 & 9 & 40,9 \\
Cukup (1-1,3) & 3 & 13,7 & 5 & 22,7 \\
Lebih (> 1,3) & 7 & 31,8 & & \\
\hline
\end{tabular}

Tidak ada perbedaan skor sindrom Tabel 5. Pengelompokkan tingkat sindrom pramenstruasi antara kelompok vegetarian dengan pramenstruasi ditunjukkan pada Tabel 6. nonvegetarian. Hasil uji beda tercantum pada

Tabel 5. Skor sindrom pramenstruasi

\begin{tabular}{lccc}
\hline \multirow{2}{*}{ Variabel } & Vegetarian $(\mathrm{n}=22)$ & Non-vegetarian $(\mathrm{n}=22)$ & \\
\cline { 2 - 3 } & $\begin{array}{c}\text { Median } \pm \text { Standar } \\
\text { Deviasi }\end{array}$ & $\begin{array}{c}\text { Median } \pm \text { Standar } \\
\text { Deviasi }\end{array}$ & p value \\
\hline $\begin{array}{l}\text { Skor sindrom } \\
\text { Pramenstruasi }\end{array}$ & $12,5 \pm 11,1$ & $17 \pm 9,3$ & $0,274^{*}$ \\
\hline
\end{tabular}

*Uji Mann-Whitney

Tabel 6. Kategori tingkat sindrom pramenstruasi

\begin{tabular}{lcccc}
\hline Tingkat & \multicolumn{2}{c}{ Vegetarian $(\mathrm{n}=22)$} & \multicolumn{2}{c}{$\begin{array}{c}\text { Non Vegetarian } \\
(\mathrm{n}=22)\end{array}$} \\
\cline { 2 - 5 } & $\mathrm{n}$ & $\%$ & $\mathrm{n}$ & $\%$ \\
\hline Tidak PMS & 15 & 68,2 & 9 & 40,9 \\
PMS ringan & 3 & 13,6 & 7 & 31,8 \\
PMS sedang & 3 & 13,6 & 6 & 27,3 \\
PMS berat & 1 & 4,5 & 0 & 0 \\
\hline
\end{tabular}


Pengelompokkan ativitas fisik didasarkan pada penghitungan WHO/FAO 1985 yang dimodifikasi WNPG VIII, 2004. ${ }^{14}$ Tidak ada perbedaan aktivitas fisik yang signifikan antara kedua kelompok. Aktivitas fisik pada kelompok vegetarian dan nonvegetarian tergolong ringan dan sedang. Tidak ada yang mempunyai aktivitas fisik berat. Hasil uji statistik tercantum pada Tabel 7.

Tabel 7. Distribusi frekuensi aktivitas fisik subjek berdasarkan kelompok vegetarian dan nonvegetarian

\begin{tabular}{lccccc}
\hline \multirow{2}{*}{ Aktivitas fisik } & \multicolumn{2}{c}{ Vegetarian $(\mathrm{n}=22)$} & \multicolumn{2}{c}{$\begin{array}{c}\text { Non-vegetarian } \\
(\mathrm{n}=22)\end{array}$} & \multirow{2}{*}{$p$ value } \\
\cline { 2 - 5 } & $\mathrm{n}$ & $\%$ & $\mathrm{n}$ & $\%$ & \\
\hline Ringan & 3 & 13,6 & 5 & 22,7 & $0,698^{*}$ \\
Sedang & 19 & 86,4 & 17 & 77,3 &
\end{tabular}

*Uji Fisher-exact

Terdapat perbedaan riwayat sindrom pramenstruasi keluarga sindrom pramenstruasi antara kelompok vegetarian dan non vegetarian $(p<0,05)$. Perbedaannya pada kelompok nonvegetarian ada 8 orang yang memiliki riwayat sindrom pramenstruasi keluarga sedangkan kelompok vegetarian tidak ada seorang pun yang memiliki riwayat sindrom pramenstruasi keluarga. Uji statistik tercantum pada tabel 8.

Tabel 8. Riwayat sindrom pramenstruasi keluarga berdasarkan kelompok vegetarian dan nonvegetarian

\begin{tabular}{|c|c|c|c|c|c|}
\hline \multirow{2}{*}{$\begin{array}{l}\text { Variabel riwayat } \\
\text { sindrom } \\
\text { pramenstruasi } \\
\text { keluarga }\end{array}$} & \multicolumn{2}{|c|}{ Vegetarian $(n=22)$} & \multicolumn{2}{|c|}{$\begin{array}{l}\text { Non-vegetarian } \\
\quad(n=22)\end{array}$} & \multirow{2}{*}{$p$ value } \\
\hline & $\mathrm{n}$ & $\%$ & $\mathrm{n}$ & $\%$ & \\
\hline Ada & 0 & 0 & 8 & 36,4 & $0,004 *$ \\
\hline Tidak ada & 22 & 100 & 14 & 63,6 & \\
\hline
\end{tabular}

*Uji Fisher-exact

Variabel status vegetarian dan riwayat sindrom pramenstruasi keluarga tidak memberikan pengaruh signifikan secara statistik terhadap skor sindrom pramenstruasi. Hasil uji statistik tercantum pada Tabel 9.

Tabel 9. Hasil uji ANCOVA

\begin{tabular}{lccc}
\hline \multicolumn{1}{c}{ Variabel } & $\beta$ & Standard Error (SE) & $p$ value \\
\hline $\begin{array}{l}\text { Kelompok vegetarian } \\
\text { dan non vegetarian }\end{array}$ & $-3,4$ & 4,6 & 0,454 \\
\hline $\begin{array}{l}\text { Riwayat sindrom } \\
\text { pramenstruasi } \\
\text { keluarga }\end{array}$ & $-1,1$ & 3,5 & 0,754 \\
\hline
\end{tabular}

Hasil penelitian menunjukkan tidak ada perbedaan rerata dan simpang baku skor sindrom pramenstruasi antara kelompok vegetarian $(15,4 \pm 2,3)$ dan nonvegetarian $(16,5 \pm 2,3)$ setelah dikontrol riwayat sindrom pramenstruasi keluarga.

\section{PEMBAHASAN}

Hubungan Derajat Sindrom Pramenstruasi dengan Status Vegetarian Subjek Penelitian
Sindrom pramenstruasi dapat dialami oleh wanita pada berbagai kalangan usia mulai dari remaja hingga dewasa. Penyebab pasti sindrom ini sampai sekarang belum diketahui secara pasti. Beberapa penelitian sebelumnya menunjukkan penyebabnya adalah genetik, ketidakseimbangan hormon, pola makan dan gaya hidup yang salah. ${ }^{15}$

Penelitian ini dilakukan pada kelompok vegetarian karena vegetarian memiliki pola makan 
sumber serat, magnesium dan piridoksin lebih banyak daripada nonvegetarian sehingga diharapkan sindrom pramenstruasi pada vegetarian tidak ada atau seminimal mungkin derajatnya dibanding nonvegetarian.

Hasil penelitian ini menunjukkan tidak ada perbedaan derajat sindrom pramenstruasi antara remaja vegetarian dan nonvegetarian. Pada penelitian ini asupan serat, magnesium dan vitamin B6 tidak berbeda antara vegetarian dan non vegetarian. Variabel perancu riwayat sindrom pramenstruasi keluarga adalah satu-satunya variabel yang berbeda secara statistik pada kedua kelompok yang kemudian dikontrol dengan uji ancova. Derajat sindrom pramenstruasi tidak dikontrol dengan aktivitas fisik karena tidak ada perbedaan aktivitas fisik antara remaja vegetarian dan nonvegetarian.

Dari hasil yang didapatkan, tidak ada perbedaan asupan serat, magnesium, dan piridoksin antara remaja vegetarian dan nonvegetarian. Hal ini disebabkan variasi makanan yang dikonsumsi hampir sama. Kondisi tersebut tidak sesuai dengan hasil penelitian yang menunjukkan diet vegetarian dapat menurunkan keluhan sindrom pramenstruasi oleh Barnard et al 2000 meskipun skor derajat sindrom pramenstruasi pada penelitian ini menunjukkan vegetarian lebih rendah dari non vegetarian. ${ }^{6}$ Hal ini disebabkan oleh subjek kelompok vegetarian pada penelitian ini hampir semuanya masih mengkonsumsi produk hewani susu dan telur, sedangkan intervensi diet vegetarian dari Barnard hanya berupa sayur sayuran, buah - buahan, serealia, dan minyak nabati. Perbedaan ini akan tampak lebih nyata bila subjek penelitian yang dipilih adalah vegan murni.

Piridoksin bersama dengan magnesium mengkonjugasi estrogen di hati agar kadar estrogen dalam darah normal. Kenyataannya dalam penelitian ini nilai piridoksin vegetarian lebih rendah daripada nonvegetarian. Banyak faktor yang menjadikan nilai piridoksin vegetarian rendah dibanding nonvegetarian. Proses pengolahan dengan pemanasan, ketersediaan bentuk aktif piridoksin pada makanan, dan kurangnya asupan sumber piridoksin juga turut memberikan kontribusi pada rendahnya nilai piridoksin. ${ }^{16}$ Vitamin B6 berkaitan dengan kofaktor sintesis neurotransmitter seperti, dopamin, serotonin, dan sintesis prostaglandin tertentu. Ketika kadar serotonin, dopamin, dan prostaglandin rendah dalam darah maka timbul gejala somatik dan afektif sindrom pramenstruasi. ${ }^{9,14,17}$ Peneliti hanya bisa mengetahui penyebabnya dari asupan yang kurang. Tak lain karena penelitian ini hanya menghitung dari asupannya saja. Jadi diperlukan pengujian lebih lanjut untuk mengetahui keadaan sebenarnya dalam darah.

Penelitian ini menunjukkan asupan magnesium kelompok vegetarian lebih tinggi daripada kelompok nonvegetarian, sehingga memungkinkan aktivasi piridoksin dalam darah lebih baik pada vegetarian, dan memiliki skor sindrom pramenstruasi lebih rendah. Pada kelompok vegetarian asupan magnesium dan piridoksin tergolong cukup karena diet ini dominan mengkonsumsi sayur dan buah-buahan yang merupakan sumber magnesium dan piridoksin. Trend tersebut tampak pada penelitian ini, tetapi tidak signifikan perbedaannya.

Magnesium diperlukan untuk proses sintesis vitamin B6 atau piridoksin. Kadar magnesium kelompok PMS lebih rendah daripada non PMS pada penelitian Abdillah. ${ }^{18}$ Penelitian ini menunjukkan kelompok nonvegetarian yang menderita sindrom pramenstruasi nilai magnesiumnya lebih rendah dari batas normal yang ditetapkan WKPN 2004. Diperlukan pengujian lebih lanjut untuk mengetahui kadar magnesium sebenarnya dalam darah dan pengaruhnya terhadap sindrom pramenstruasi.

Masyarakat umum selalu mengkaitkan diet vegetarian dengan asupan seratnya yang lebih banyak daripada yang nonvegetarian. Perlu diketahui antar jenis vegetarian murni dengan lacto-ovo vegetarian berbeda variasi makanan yang dikonsumsi dan hal itu mempengaruhi pada asupan seratnya. Serat yang dikonsumsi oleh vegan murni jauh lebih banyak daripada lacto-ovo vegetarian. ${ }^{19}$ Kondisi tersebut yang mengakibatkan hasil uji beda antara vegetarian dan nonvegetarian pada penelitian ini tidak menunjukkan perbedaan yang signifikan.

Review artikel oleh Rejina Diekemper menunjukkan diet vegetarian yang tinggi serat mengekskresikan lebih banyak estrogen pada fesesnya dan kadar estrogen bebas dalam darah 50 $\%$ lebih rendah daripada omnivor. Hal ini mengakibatkan pada vegetarian lebih sedikit yang mengalami sindrom pramenstruasi. Berbanding terbalik dengan hasil penelitian ini yang menunjukkan kecenderungan makin tinggi asupan serat, makin tinggi sindrom pramenstruasinya. Hasil ini lebih sesuai dengan hasil penelitian Gaskin et al bahwa diet tinggi serat justru meningkatkan risiko sindrom pramenstruasi melalui mekanisme penurunan level hormon estradiol, progesterone, LH, dan FSH yang 
mengganggu siklus menstruasi seorang wanita. ${ }^{20}$ Hal ini juga berlaku untuk asupan magnesium dan piridoksin. Perlu pembuktian lebih lanjut mengenai serat dan bagaimana prosesnya terhadap sindrom pramenstruasi.

\section{KETERBATASAN PENELITIAN}

Pengisian kuesioner

pramenstruasi yang bersifat subjektif. Tidak dilakukan uji bioaktif kadar magnesium dan vitamin B6 dalam darah.

\section{SIMPULAN}

Tidak terdapat hubungan status vegetarian dan derajat sindrom pramenstruasi baik sebelum dan setelah dikontrol riwayat sindrom pramenstruasi keluarga.

\section{SARAN}

Mengkonsumsi banyak sumber magnesium dan vitamin B6 yang berpotensi untuk meredakan gejala sindrom pramenstruasi.

\section{DAFTAR PUSTAKA}

1. Premenstrual Syndrome. The American College of Obstetricians and Gynekologists. 2005.

2. Amita Singh, Dukhu Kiran, Harminder Singh, Bithika Nel, Prabhakar Singh, dan Pavan Tiwari. Prevalence and Severity of Dysmenorrhea: A Problem Related to Menstruation, among First and Second Year Female Medical Students. Indian J Physiol Pharmacol 2008; 52 (4) [cited 2012 April 27]: 389-397.

3. Anandha Lakshmi S. Priy M, Saraswathi I, Saravanan A, Ramamchandran C. Prevalence of Premenstrual Syndrome and Dysmenorrhoea among Female Medical Students and its Association with College Absenteeism. Int J Biol Med Res. 2011; 2(4) [cited 2012 April 27]: 1011 1016. Available from : URL : www.biomedscidirect.com.

4. Antai A.B, Udezi A. W, Ekanem E. E, Okon U.J, dan Umoiyoho A. U. Premenstrual Syndrome: Prevalence in Students of University of Calabar, Nigeria. African Journal of Biomedical Research, Vol. 7 (2004) [cited 2012 November 25]; 45 -50.

5. T. Takeda, K. Tasaka, M. Sakata, dan Y. Murata. Prevalence of Premenstrual Syndrome and Premenstrual Dysphoric Disorder in Japanese Women. Arch Womens Ment Health (2006) [cited 2012 November 25] 9: 209-212.

6. Neal D. Barnard, Anthony R. Scialli, Donna Hurlock, Patricia Bertron. Diet and Sex-Hormone Binding Globulin, Dysmenorrhea, and Premenstrual Symptoms. Elsevier. 2000 [cited 2012 November 25].
7. Bonnie Farmer, Brian T. Larson, Victor L. Fulgoni, Alice J. Rainville, George U. Liepa. Nutrient-Dense Approach to Weight Management: An Analysis of the National Health and Nutrition Examination Survey 1999-2004. J Am Diet Assoc. 2011[cited 2012 November 25].111:819-827.

8. Rejina Diekemper. Conservative Treatment for Premenstrual Syndrome. [cited 20126 Desember] Available from: URL: logan.edu

9. Mayo JL. Premenstrual Syndrome A Natural Approach to Management. Advanced Nutrition Publications 1999 [cited 2012 November 25]:5:1-8.

10. De Souza MC, Walker AF, Robinson PA, Bolland K. A synergistic effect of a daily supplement for 1 month of $200 \mathrm{mg}$ magnesium plus $50 \mathrm{mg}$ vitamin B6 for the relief of anxiety-related premenstrual symptoms: a randomized, double-blind, crossover study. J Womens Health Gend Based Med 2000[cited 2012 November 25] ;9:131-9.

11. Margie Lee Gallagher. The Nutrition and Their Metabolism: Krause's Food \& Nutrition Therapy 12th ed. USA. Elsevier; p.89

12. IMT/U untuk Usia $5-18$ tahun standar WHO 2005. WHO Anthro Plus.

13. Meir Steiner, Miki Peer, Eva Palova, Ellen W. Freeman, Mary Macdougall and Claudio N. Soares. The Premenstrual Symptoms Screening Tool revised for Adolescents (PSST-A): Prevalence of Severe PMS and Premenstrual Dysphoric Disorder in Adolescents. Arch Womens Ment Health (2011) [cited 2012 November 25]: 14:77-81.

14. WHO/FAO 1985 yang dimodifikasi WNPG VIII, 2004. Available from: URL: dinkes.jogjaprov.go.id/gizi/index.php/home/hal_pe nting

15. Uriel Halbreich. The etiology, biology, and evolving pathology of premenstrual syndromes.

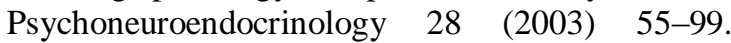
Available from: URL: www.elsevier.com/locate/psyneuen.

16. Shyamala Dakshinamurti, dan Krishnamurti Dakshinamurti. Handbook of Vitamin $4^{\text {th }}$ edition. Taylor \& Francis Group (2007) [cited 2012 November 24]: 319.

17. Radha Indusekhar, Sa'adatu B. Usman, Shaughn O'Brien. Psychological Aspects of Premenstrual Syndrome. Best Practice \& Research Clinical Obstetrics and Gynaecology Vol. 21, No. 2, pp. 207-220, 2007. Available from: URL: /www.sciencedirect.com.

18. Abdillah, T. Jeffrey. Kadar Serum Magnesium Terhadap Gambaran Sindrom Premenstruasi Yang Dinilai Dengan Premenstrual Syndrome Scale [tesis]. Medan: USU ; 2011. Available from : URL www.repository.usu.ac.id/handle/123456789/27641

19. A.Waldmann, JW. Koschizke, C. Leitzmann and A. Hahn. Dietary Intakes and Lifestyle Factors of a 
Vegan Population in Germany: Results from the German Vegan Study. European Journal of Clinical Nutrition (2003) 57, 947-955. Available from: URL: www.nature.com/ejcn.

20. Audrey J Gaskins, Sunni L Mumford, Cuilin Zhang, Jean Wactawski-Wende, Kathleen M Hovey, Brian W Whitcomb, Penelope P Howards, Neil J Perkins, Edwina Yeung, and Enrique F Schisterman. Effect of daily fiber intake on reproductive function: the BioCycle Study. Am J Clin Nutr 2009. [cited 2012 November 25]; 90:1061-9. 